\title{
Advance control of a fully integrated energy system for a building
}

\author{
J. M. Counsell, Al-Khaykan Ameer, M. J. Stewart \\ School of Electrical Engineering, Electronics and Computer Science \\ University of Liverpool, $U K$ \\ Liverpool University and Faculty of Engineering at Al-Qadisiyah University, Iraq
}

\begin{abstract}
Commercial Buildings are no longer just national heat and power network energy loads, but they are becoming part of a smarter grid by including their own dedicated heat and power generation. A building integrated approach of Combined Heat and Power (CHP) generation and photovoltaic power generation (PV) known as Combined Heat and power with PV (CHPV) is emerging as a complementary energy supply solution to conventional boilers in the design of sustainable commercial buildings and local energy systems. The merits for the building user/owner of this approach are; to reduce life time energy running costs; reduce carbon emissions to contribute to UK's 2020/2030 climate change targets and provide a more resilient energy supply solution. Soft target markets for CHPV are building clusters such as; public buildings such as hospitals, colleges, universities and buildings and private sector complexes such as retail parks and science parks. The control methodology of CHPV systems is the main research challenge to provide reliable system performance to enhance the successful deployment of these systems. The CHPV solution provides all heating, ventilating and air-conditioning (HVAC) facilities as well as electrical power supply. This power is generated by a locally connected CHP system electrically connected to a private wire network (PWN) which simultaneously allows the utilisation of building side installed PV power generation to be shared with all buildings in the cluster/complex. This paper presents a novel CHPV system design topology for robust, reliable and high performance control of building temperatures and energy supply from the local energy system. This system's topology includes; a hot water network; a central hot water storage system to supply heat to the building; electrically powered ventilation and cooling in the building; a centralised CHP engine and control; centralised gas boiler supply; a thermal hot water store for the heat network and its control; PV array installed on the building and backup/supplementary power provided by the national grid. The advanced control system solution presented in this paper, aims to achieve desired building temperatures using thermostatic control whilst simultaneously tracking a specified national grid power demand profile. The results from simulations presented in the paper show the efficacy of the novel control strategy of CHPV and complementary gas boilers to control energy utilisation of the building's heat and power whilst tracking a required national grid power demand.
\end{abstract}

Keywords: CHP, control, heat storage, photovoltaics, heating and cooling

\section{Introduction}

The built environment is responsible for almost half of all carbon emissions from energy use in Europe and is therefore a primary target for mandated demand reduction through ongoing initiatives such as Energy Performance of Buildings Directive EPBD [1]. Distributed generation and control has a significant role in reducing demand and emissions at micro grid/ local energy system level. This is achieved by introducing energy a power supply system that utilises its heat by-product and complements other plant such as gas boilers and supports other energy efficiency measures, such as building refurbishment projects with better insulation and energy efficient appliances. CHP is an increasingly

Manuscript received April 10, 2016; revised October 19, 2016.

Corresponding author. Tel: 00447459204882; E-mail address:hsaalkh3@liverpool.ac.uk

doi: 10.12720/sgce.5.4.229-236 
attractive option to locally generate both heat and electricity from a single machine. The very high rated efficiency of a system featuring a gas fired reciprocating CHP engine assumes full utilisation of heat generated in operation. For a modern building with relatively low heat loss, the correct CHP plant sizing should ensure as much as possible that heat generation is utilised within the local network during winter months, with top-up from gas boilers as required. In summer months however, there is a very low heat demand at a time when demand for cooling is increased. Building integrated PV is also an attractive option to locally generate zero carbon electricity in isolation or as part of a suite of sustainability measures featuring CHP. PV complements a local CHP system by generating zero carbon electricity at a time of year and time of day when electrical demand from cooling is highest. Integrated CHP and PV systems will be increasingly important as building construction and thermal performance meets or exceeds energy and environmental assessment standards such as SBEM, SAP and BREEAM [2]-[4]. For low loss commercial buildings, previous work has utilised thermal energy storage to improve the balance of local heat supply with heat demand and regulate the system for improved energy performance [5]. A method of sizing relative scales of electrical and thermal demands with CHP and PV capacities is presented in this paper in support of the combined and complementary CHP and PV concept. The control strategy designed using multiple input multiple output controller design methods uses three separate single input single output control loops. They control and integrate the operation of the CHP gas supply, building heat demand and the heat taken or supplied from the thermal store in the presence of PV systems. A supplementary control operates the gas boiler. The aim of the controller was chosen for energy regulator rules to target a desired electrical demand profile from the national grid whilst maintaining a desired building temperature. To present this multi-vector strategy, a representative dynamic thermal model of the building is required. Validation of this model for its use in control system design is detailed in [6], [7], [9]. This heat and temperature prediction model for the building was implemented in Matlab/Simulink and integrated with other dynamic Simulink models of the CHP engine, heat network, thermal store and the control systems.

\section{Controller Design and Simulation Methodologies}

The control algorithm for the controllers in the CHPV system was designed using the RIDE methodology [6] to create a robust independent controller for the CHPV system as shown in Fig. 1 . This controller tracks a desired power demand from the national grid (e.g. set to zero watts in this case) and a target heat network temperature. The RIDE design method showed that three primary Single Input Single Output (SISO) control systems could robustly decouple heat and power control. These SISO tracking control systems were specified as follows:

a) A feedback control system that tracks desired national grid demand by regulating the gas power supplied to the CHP engine.

b) A feedback control system that tracks a set point temperature for the average temperature of the heat network (e.g. $80^{\circ} \mathrm{C}$ ) by regulating the target temperature for the average temperature of the hot water tank thermal store.

c) A feedback control system to track the desired building temperature by regulating the heat delivered by the heat network to building heat exchanger.

A secondary supplementary control operates the back-up gas boiler only when CHP is at maximum output and the average water network temperature is below a set point. Whilst the controllers are noninteracting systems, they were designed using a multi-input multi-output design philosophy RIDE [6], [7]. The novel system topology has created a remarkable and simple solution to decouple the interaction between heat and power that exists with all CHP based solutions. The control also allows tracking of target set points in the presence of multiple heat [9] and power disturbances such as the power generated by on-site renewables such as PV. A Matlab/Simulink model was developed to incorporated models of the three SISO control systems and supplementary boiler control to test this new electrically led CHP engine and the heat network control strategy. This strategy in addition to models mentioned also modelled 
the thermostatic control of the buildings by controlling the heat flow from the heat exchanger in the heat network to maintain the required thermal comfort temperature $21^{\circ} \mathrm{C}$ (including an optimum start and at night time set point of $12^{\circ} \mathrm{C}$ ) and a chiller compressor for electrical cooling of the building when the building temperature exceeds $24^{\circ} \mathrm{C}$. The controller of CHP engine follows the electrical demand of the building and at same time pumps the heat generated into the heat network. When the building has enough heat to maintain the thermal comfort requirements and the CHP has surplus heat, the controller directs the surplus of heat to the heat storage. In the case the CHP does not have enough heat and the building requires more heat to maintain comfort then the heat storage will pump heat back into the heat network. If the combined CHP and thermal store heat supplies still cannot provide enough heat, the gas boiler control operates to top up any heat supply deficit. The total CHPV system modelled and simulated in this paper consist of 350kWE CHP engine with back-up gas boiler; $600 \mathrm{~m}^{2}$ of photovoltaics panels; a hot water network; Heat ex-changer + thermostat; and $785 \mathrm{~m}^{3}$ tank of water for thermal storage.

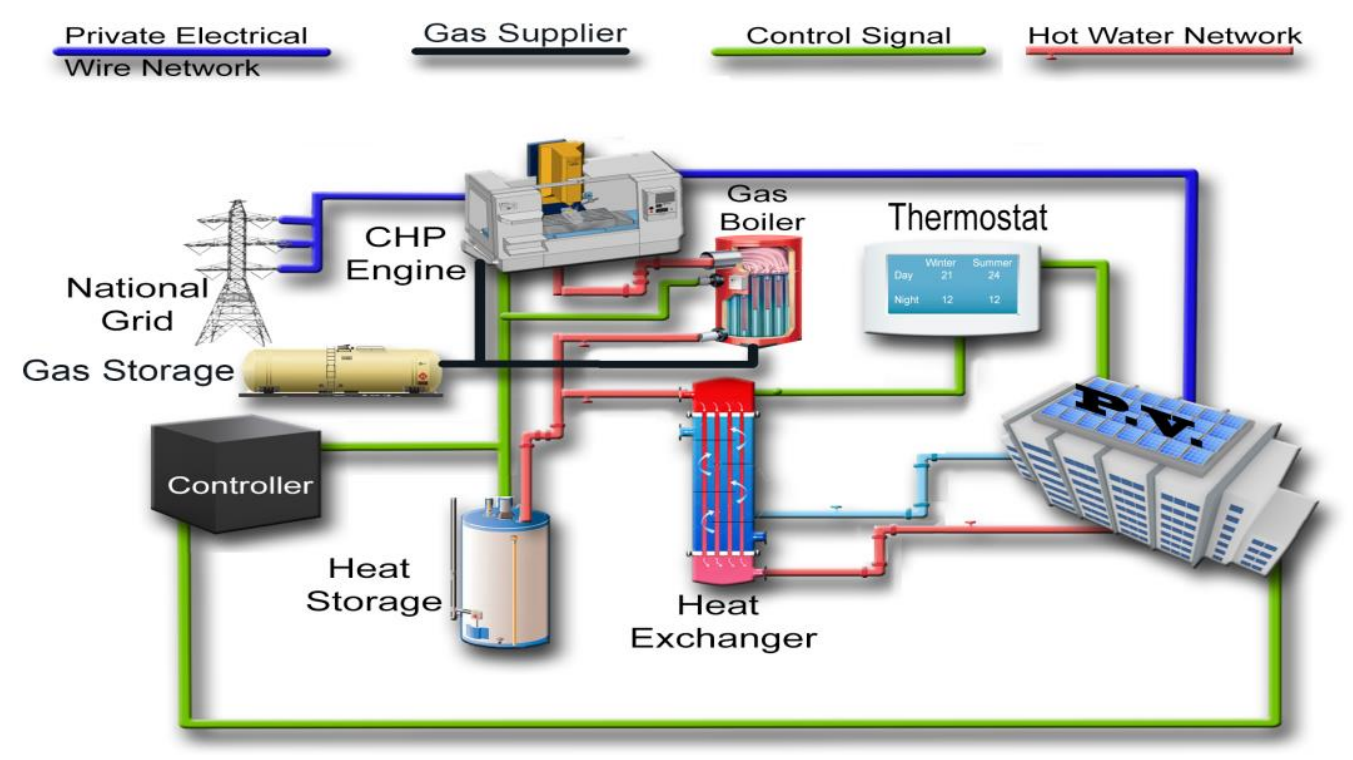

Fig. 1. Schematic of CHPV system topology.

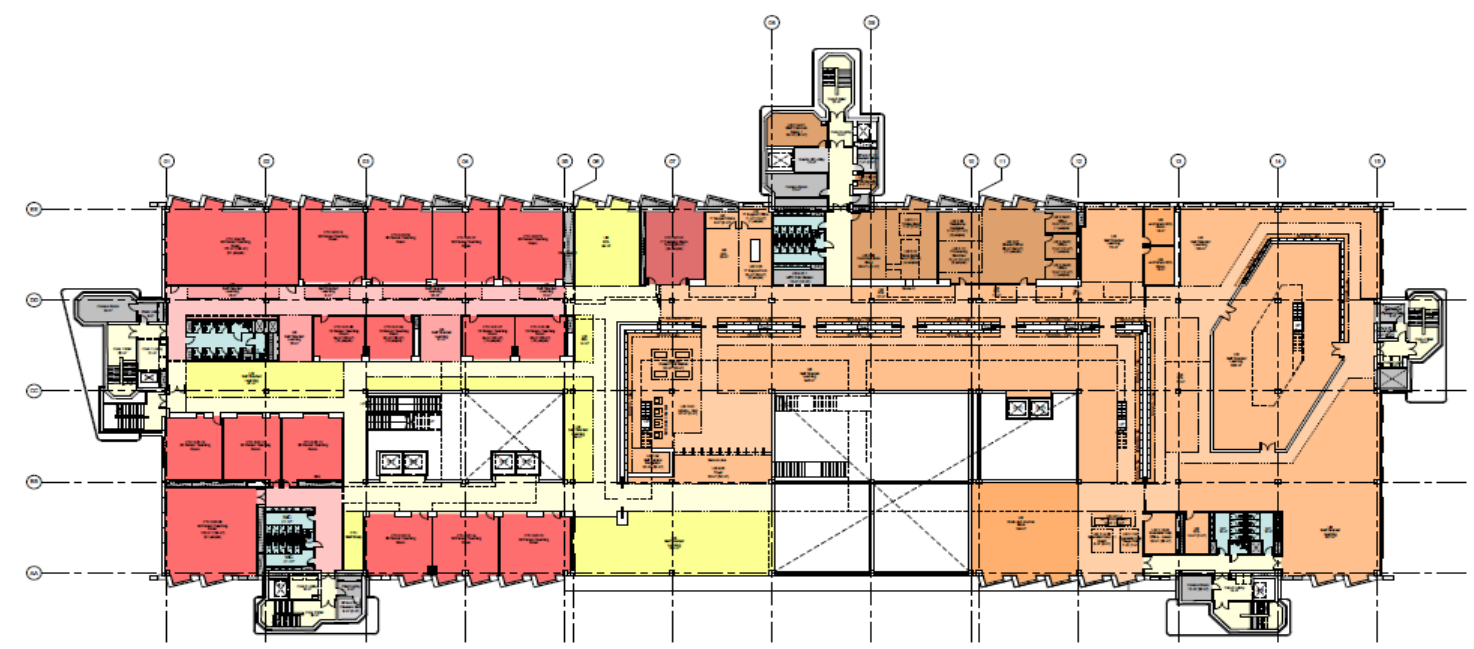

Fig. 2. The proposed layout of the building. 


\section{Model: Building Physics Calibration}

The building demand models used in this paper are based on previously validated models against SAP and EN 15265 European Standard for Energy Performance of Buildings [7]-[9]. SAP and other compliance methods such as SBEM and IES refer extensively to empirical NCM datasets. The model adaption in this paper uses these datasets to extend validation to non-domestic buildings.

\section{Case Study: Building's Model}

In this paper, a building is considered with footprint of $125 \mathrm{~m} \times 40 \mathrm{~m}$ on seven floors, giving a gross conditioned area of $35000 \mathrm{~m}^{2}$. The CHP engine is inside the building and the efficiency of the engine is assumed to be $84 \%$ divided to $(42 \%)$ as electricity and the other (42\%) as CHP engine generated heat. The building is designed for light to medium educational requirements and electricity demand profiles to reflect this from NCM datasets where selected [3]. Its uses are multi-purpose, for example; library, sports hall, classrooms, lecture theatres and canteens etc.

\section{Results}

This section presents results obtained using MATLAB/Simulink modelling and simulation software. This section focuses on the primary system of CHP and PV. Effect of the gas boiler is removed from the results to highlight CHPV operation. Fig. 3 shows the temperatures inside the building (Red Line), (Green Line) outside the building during whole year and the set point of building temperature (Blue Line). The temperature set points of the building are:

1- Heating set point $21^{\circ} \mathrm{C}$ in daytime and $12^{\circ} \mathrm{C}$ at night.

2- Cooling set point is $24^{\circ} \mathrm{C}$.

Fig. 3 shows how the CHPV engine controller control and heat network thermal storage control contributes to the temperature of building during the whole year. In the winter at the start of the simulation period (1 January) and end of period (31 December) the building temperature shows some shortfall due to insufficient heat from the CHP engine and store. During these times, the building will require supplementary heating from the gas condensing boiler to achieve setpoint tracking. During spring autumn and summer months, Fig. 3 shows the building temperatures follow the set point very accurately both in heating and cooling modes of operation. Fig. 4 shows the accuracy of the temperature (red) control tracking in the building for 6 consecutive days in January. The set point (blue) moves up from $12^{\circ} \mathrm{C}$ to $21^{\circ} \mathrm{C}$ in the mornings using and pre-heat ramp in set point temperature. This ramp in desired temperatures is important for two reasons:

1) To reduce the peak heat demand at the start of an occupancy period. This minimises the need for supplementary heating from the gas boiler.

2) To create a useful and efficient use of heat during the un-occupied period to allow the CHP engine to generate electricity at a low electricity demand period whilst efficiently utilise the generated heat without the need for thermal storage.

In order to achieve such accurate temperature control, the heat network temperature must also be accurately controlled despite many sources of heat disturbance and the dynamic nature of building heat demand. The heat network comprising CHP and gas supplies is thermostatically controlled by using the thermal store as an active load. For example when the heat network temperature is too high, the boiler would be switched off first. If the network temperature is still high, the CHP engine heat is directed to the store. When it is too low, it is taken form the store. If it is still too low, the gas boiler would supplement the supply. These conditions prevent gas boiler heat ever being stored. The minimum temperature in the heat storage has been set it as $50^{\circ} \mathrm{C}$. As Fig. 5 shows there is no CHP supplied heat in heat storage in cold time of year, whilst at the warmer periods it stores the surplus heat as seen by rise in the average temperature of the store. By summer time if the CHP engine is required to run to supply electricity, the store reaches its maximum temperature of $95^{\circ} \mathrm{C}$. In Fig. 6 the control signal (blue) for the heat storage 
system is shown for 6 days in January. It shows the control of the heat store modulating during the day to keep a steady heat network temperature and the store being drained of heat during the night when the CHP engine heat generated is very low. Within its operational range, the CHP engine is controlled to drive the national grid power demand to be equal to zero at all times. This means the CHP generated power must follow the building electrical NET demand (i.e. building electrical demand minus any demand side generation e.g. from PV) second by second. Fig. 7 shows for four weekdays that the building needs to transiently import from national grid when the electrical power generated by the CHP and photovoltaics arrays is not enough to meet the electrical building demand. At the weekend however, the CHP engine and photovoltaic generated electricity can reach all the building's demand. Thus, Fig. 7 shows zero national grid demand (blue) at the weekends (i.e. no export or import of electricity). Fig. 8 shows the control signal (blue) of the CHP engine to follow the NET building demand as previously described, for a 6 day period in January, highlighting the control system reacting to the injection of PV power generation with the dips in control action during the occupied periods both on weekdays and weekends. Fig. 8 also demonstrates that the CHPV system is capable of efficiently following the electrcity demand as it varies daily and by the day of the week, showing much lower generation at the weekends. Fig. 9 shows the cumulative efficiency of the total fully integrated CHPV system as it varies throughout the year, peaking in deep winter at $87 \%$ when almost all of the gnerated CHP heat is utilised to heat the building. This is greater than the efficiency of the CHP engine of $84 \%$ due to the PV power generation which is assumed to be $100 \%$ efficient at the same time. The resulting end-of-year efficiency taking into account the warmer months reduces to just over $80 \%$.

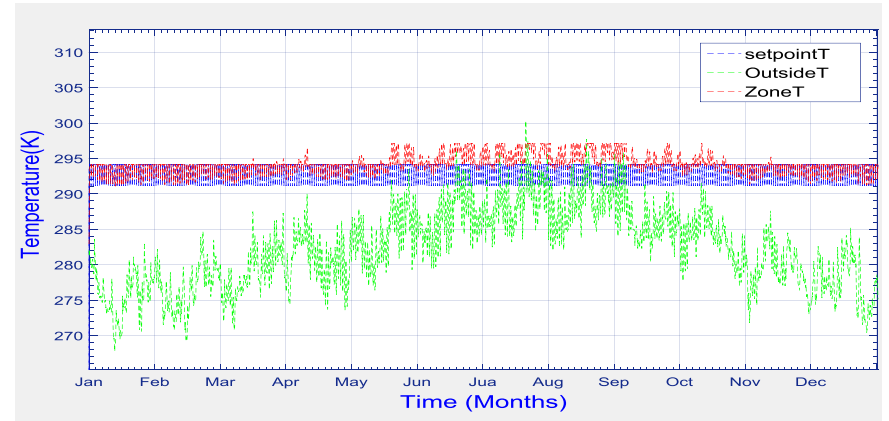

Fig. 3. Building temperature for the year.

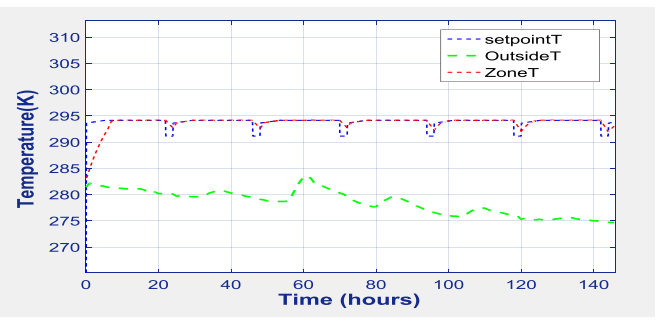

Fig. 4. Building temperature for 6 Days in January.

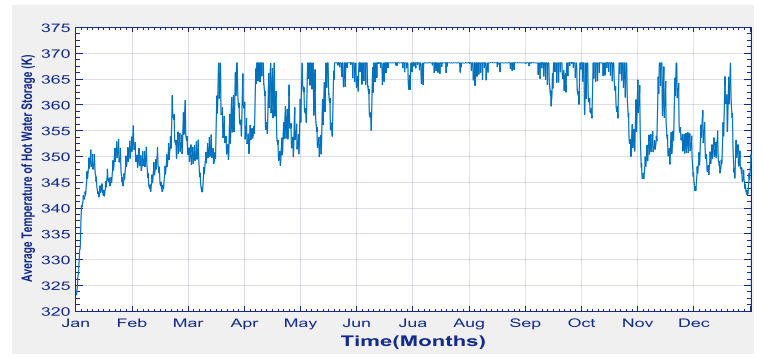

Fig. 5. Average heat storage temperature $\left({ }^{\circ} \mathrm{C}\right)$. 


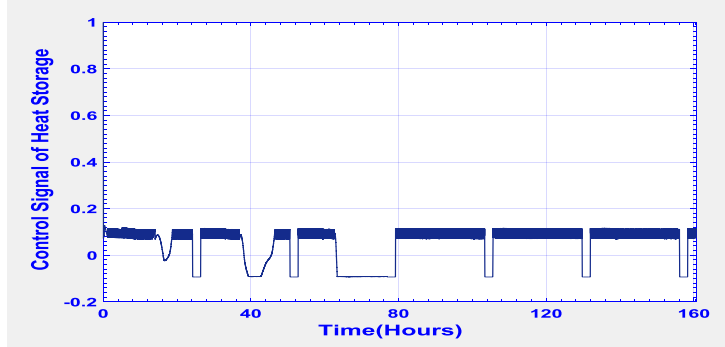

Fig. 6. Control signal of heat storage.

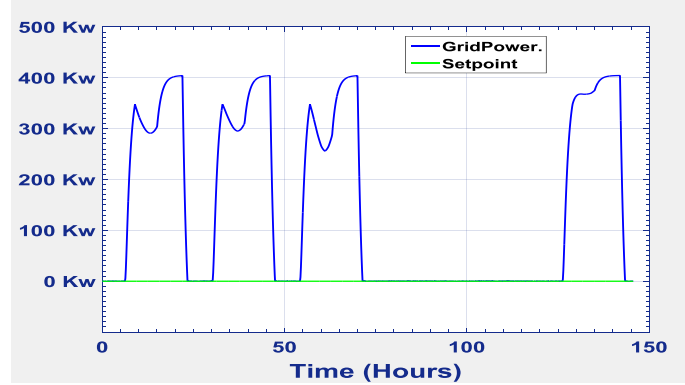

Fig. 7. National grid power demand in watts for 6 days in January.

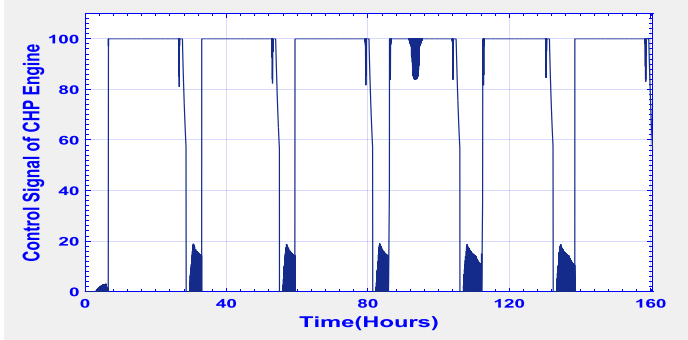

Fig. 8. Control signal of CHP engine.

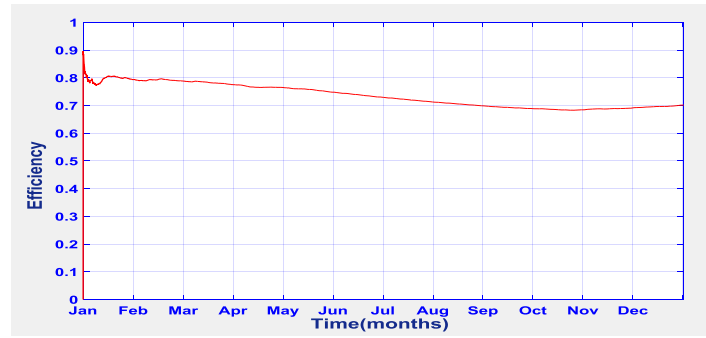

Fig. 9. CHPV total efficiency over the year period.

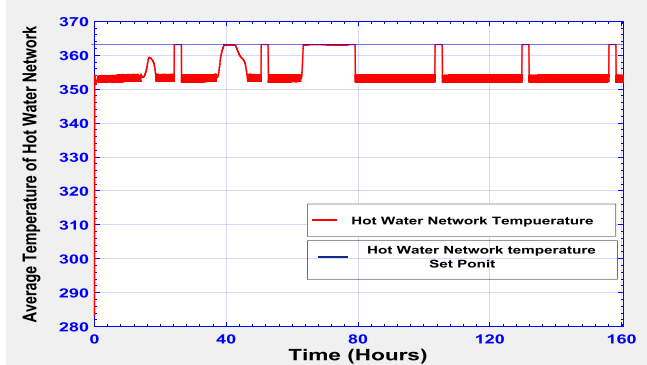

Fig. 10. Average temperature of hot water network for 6 Days in January. 


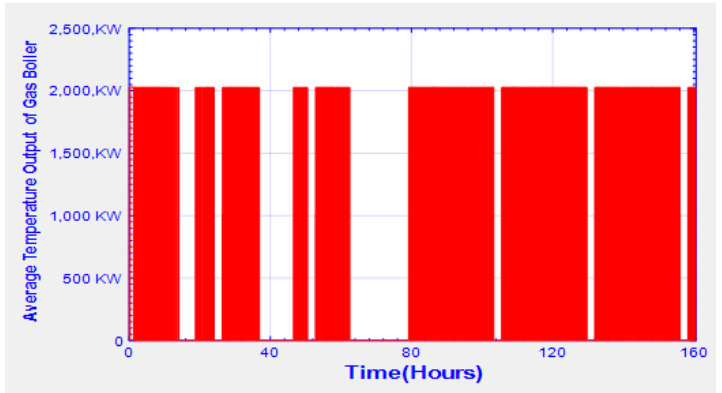

Fig. 11. Amount of heat from gas boiler for 6 Days in January.

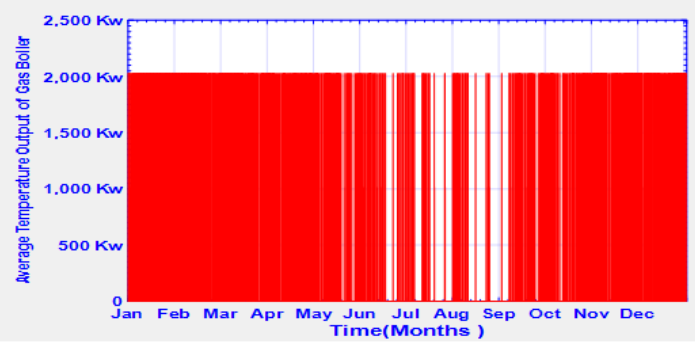

Fig. 12. Amount of heat from gas boiler for 12 Months.

\section{Conclusion}

In conclusion, a Matlab/Simulink model has been developed to simulate the application of a advanced control system topology for a fully integrated CHP and PV system (CHPV). It has been demonstrated in simulation to operate with excellent performance when applied to a typical educational building based on a real life case study. (e.g. LJMU's new education building in Liverpool with acknowledgement here to Arup North West UK's contribution to provide basic data on this building). This model has been used to present results that demonstrate that an electrical led control system for the CHP engine can track a desired national grid power demand profile (in this case zero import and export power) whilst simultaneously tracking the building's desired temperature for thermal comfort. The use of optimum start on building temperature control enables better utilisation of heat generated by the CHP and the thermal store can be used to minimise the need for gas boiler supplementary heating. The introduction of PV or any other demand side renewable power system integrated with the demand side's Private Wire Network (PWN) can be accommodated by ensuring the CHP engine is controlled to follow net electric demand as opposed to heat demand.

\section{Future Work}

Future work of the project has divided in two parts:

- Using this strategy to add more building and zones to system and we can get same results as one building because the new methodology is to control the hot water network not the temperature of a building direct

- For example Iraq has hot season for 9 months for that the next step is adding (absorber chiller) to the system which is become suitable for all different weather types and temperature. The absorber chiller need to develop the MATLAB Model and new cold water system.

\section{Copyright}

All authors must sign the Transfer of Copyright agreement before the article can be published. This transfer agreement enables ETP (Engineering and Technology Publishing) to protect the copyrighted 
material for the authors, but does not relinquish the authors' proprietary rights. The copyright transfer covers the exclusive rights to reproduce and distribute the article, including reprints, photographic reproductions, microfilm or any other reproductions of similar nature and translations. Authors are responsible for obtaining from the copyright holder permission to reproduce any figures for which copyright exists.

\section{Acknowledgement}

This research is funded by EPSRC and Innovate UK through the Local Energy Systems research programme. (Refer BRE \& University of Liverpool, CHPV project)

\section{References}

[1] Directive 2002/91/EC of the European Parliament and of the Council of 16 December 2002. [Online]. Available: http://eurlex.europa.eu/legal-

content/EN/ALL/ELX_SESSIONID=FZMjThLLzfxmmMCQGp2Y1s2d3TjwtD8QS3pqdkhXZbwqGwlgY9KN!2064651424 ?uri=CELEX\%3A32010L0031

[2] Standard Assessment Procedure. [Online]. Available: http://www.bre.co.uk/sap2012/

[3] Simplified Building Energy Model. [Online]. Available: http://www.uk-ncm.org.uk/

[4] BRE. Environmental Assessment Methodology, [Online]. Available:http://www.breeam.com/

[5] Mago PJ, et al., Analysis and optimization of the use of CHP ORC systems for Small Commercial Buildings, Energy \& Buildings, 42, 2010.

[6] Counsell JM, Ameer K, Stewart M. CHPV Control. IET Faraday Workshop, Calcutta India, 2015. Online: At IET Conferences.

[7] Counsell JM, Murphy GB, Allison J. Control of micro-CHP and thermal energy storage for minimising electrical grid utilisation. International Journal of Low-Carbon Technologies Advance Access Published, August 21, 2014.

[8] British Standards Institution, BS EN 15265: British Standards Institution, London, UK, 2007.

[9] Counsell JM, Murphy GB, Allison J, et al., Calibrating a combined energy systems analysis and controller design method with empirical data. Exergy International Journal, 2013; 57:484-494. 